\title{
Materials ultralleugers: la importància de Pestructura tridimensional
}

David Ferrer Sánchez (davidferrersanchez@gmail.com) Graduat en Nanociència i Nanotecnologia. Centre de Recerca per a l'Educació Científica i Matemàtica (CRECIM).

La microxarxa és l'estructura metàl-lica més lleugera que s'ha creat. Amb un 99,99\% d'aire, és suficientment lleugera com per sostenir-se sobre un dent de lleó, mentre que la seva estructura la fa resistent. Aquest material, com l'aerografit o l'aerogel de grafè que són fins i tot més lleugers, formen part d'una nova generació de materials ultralleugers que ens permeten observar que les propietats no només depenen d'allò que estan formats els materials, sinó també de la seva estructura 3D. En aquest context, les tècniques de fabricació utilitzades resulten molt importants per al desenvolupament dels nous materials del segle XXI.

Paraules clau: Microxarxa, materials ultralleugers, estructura 3D i tècniques de fabricació.

The microlattice is the lightest metallic structure ever made. At 99.99\% air, it's light enough to balance on top of a dandelion, while its structure makes it strong. This material, such as aerographite or graphene aerogel which are even lighter, are part of a new generation of ultralight materials that allows us to observe that properties do not only depend on what materials are made but also on their 3D structure. In thid context, the manufacturing techniques used are very important for the development of the new materials of the 21st Century.

Keywords: Microlattice, ultralight materials, 3D structure and manufacturing techniques.

\section{LA MICROXARXA: L'ESTRUCTURA METÀL-LICA MÉS LLEUGERA MAI VISTA}

El passat mes d'octubre l'empresa Boeing, una de les principals fabricants d'avions comercials i d'equips aeroespacials del món, publicava un vídeo en el qual presentava "l'estructura metàl•lica més lleugera mai vista, formada per un 99,99\% d'aire". L'han anomenada microxarxa i en el vídeo publicat es pot veure entre altres característiques com aquesta estructura se sosté sobre el pol•len d'un dent de lleó sense deformar-lo (veure Figura 1) així com la seva elevada capacitat per absorbir energia. Per demostrar les seves qualitats, en el vídeo els creadors expliquen que si llancéssim un ou des d'un vint-i-cinquè pis recobert per la microxarxa, l'ou arribaria a terra sense trencar-se.

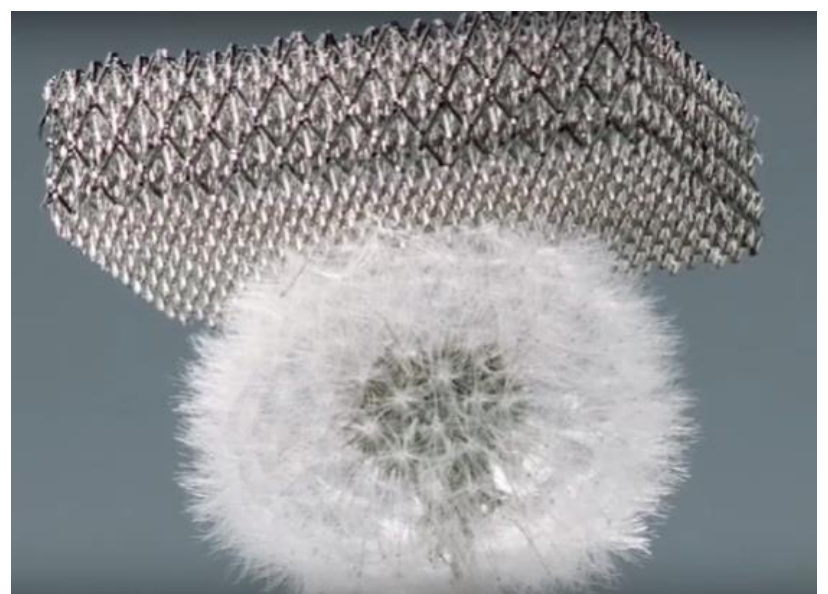

Figura 1. Prototip de la microxarxa de níquel sospesa sobre un dent de lleó. 
El cert és que aquest nou material que l'empresa està promocionant a través de la xarxa va ser desenvolupat per primera vegada en 2011 per HRL Laboratories - propietat de General Motors Corporation i Boeing - en col-laboració amb la Universitat de Caltech i de California. L'estructura es basa en una microxarxa de tubs metàl-lics, barreja de níquel i fòsfor, buits per dins. Aquests, per la seva banda, es troben entrellaçats formant una àmplia xarxa de cel-les octaèdriques (veure Figura 2).

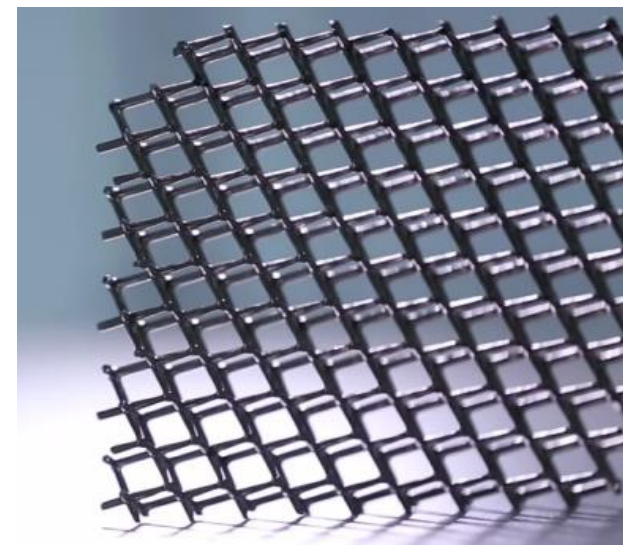

Figura 2. Estructura tridimensional de la microxarxa de níquel.

Entre les particularitats d'aquest material es troba l'amplada de la paret dels tubs que és de tan sols 100 nanòmetres - 1000 vegades més prim que el cabell humà - i la seva estructura ordenada i jeràrquica de tubs que millora significativament les propietats en relació a les estructures metàl-liques conegudes.

La microxarxa és un exemple més del que podríem catalogar com a material bio-inspirat: materials que intenten imitar d'altres ja existents en la natura. En concret, intenta imitar l'estructura típica dels ossos humans, que malgrat ser rígids per fora són buits internament. D'aquesta forma s'aconsegueix que siguin lleugers sense que això signifiqui que es trenquin fàcilment, més bé tot el contrari. Específicament, s'ha aconseguit que l'estructura sigui menys densa $(0,9 \mathrm{mg} / \mathrm{cm} 3)$ que les d'alguns aerogels 0 altres escumes ultralleugeres, com la que fins en el seu moment era considerada la menys densa: l'aerogel de sílica (1 mg/cm3). Però, alhora, la microxarxa exhibeix propietats inesperades per a una estructura metàl-lica tan lleugera, com és l'elevada resistència, la gran capacitat de ser deformat quan se li aplica una força (mòdul de Young) o l'alta capacitat per absorbir energia i recuperar la forma després de ser comprimides per sobre d'un $50 \%$ de tensió (veure Figura 3).

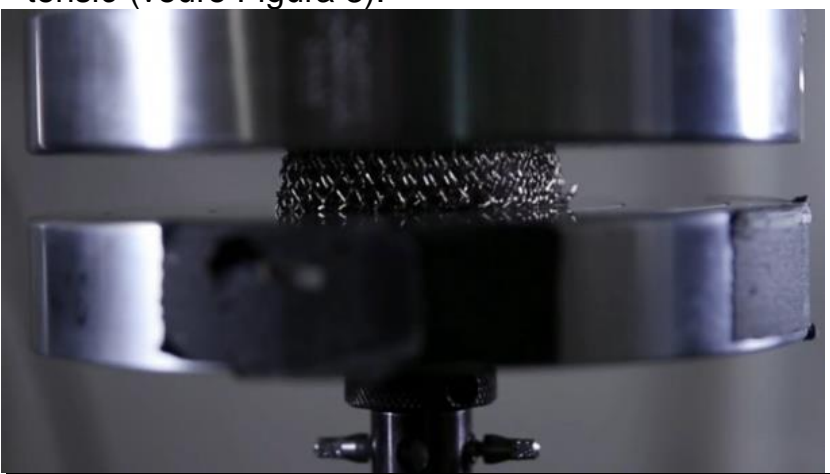

Figura 3. Microxarxa de níquel sotmesa a un procés de compressió.

La investigació en aquest tipus d'estructures ultralleugeres i les seves propietats fan pensar en una àmplia llista de potencials aplicacions, com pot ser la construcció d'aïllants tèrmics; aïllants de vibracions i absorció de xocs; suports catalítics; o elèctrodes de bateries. A més, en la indústria automobilística, aeronàutica i aeroespacial la tecnologia de les microxarxes pot ser interessant per aconseguir estructures més lleugeres i més eficients energèticament.

En aquesta direcció es pronuncia Bill Carter, director del laboratori de sensors i materials de HRL Laboratories, que creu que és probable que la primera aplicació sigui la seva utilització en coets espacials que Boeing planeja construir en uns 5 anys, mentre que el seu ús en avions comercials es produiria en els 5 anys posteriors a l'ús en coets. Sembla ser però, en paraules del mateix Bill Carter, que l'aplicació en la indústria automobilística encara haurà d'esperar més, fins que el cost de fabricació del material no es redueixi per tal que sigui econòmicament viable. Malgrat la companyia Boeing no ha anunciat els plans definitius sobre quina serà la funció concreta de la microxarxa de níquel en coets $\mathrm{i}$ avions, tot indica que podria ser utilitzada per a la construcció de panells de les parets 0 del terra. D'aquesta manera, s'aconseguiria una reducció del pes dels aparells, un element crucial en el seu disseny i fabricació.

\section{La importància d'aconseguir materials lleugers}

Crear materials més lleugers no és una preocupació actual, sinó que ha aparegut històricament, i té la seva base en la segona llei de Newton o llei fonamental de la dinàmica. La segona llei de Newton ens diu que el canvi de moviment és proporcional a la força motriu exercida i ocorre 
segons la línia recta al llarg de la qual aquesta força s'exerceix. L'acceleració que adquireix un cos serà, per tant, proporcional a la força neta aplicada sobre el mateix, sent la constant de proporcionalitat la massa del propi cos (expressat matemàticament: Força = Massa $x$ Acceleració). Així doncs, per a aconseguir una mateixa acceleració en un cos, la força aplicada sobre aquest haurà de ser major quan major sigui la seva massa. Per tant, si hom vol moure un objecte, quan més lleuger sigui aquest objecte millor, perquè significarà que la força que s'haurà d'exercir serà menor. Tenint en compte, que l'energia en forma de treball requerida per moure un objecte es defineix matemàticament com la força exercida en la direcció del moviment multiplicada pel desplaçament del propi objecte; quan major sigui la força a exercir, major serà l'energia necessària per fer moure l'objecte. D'aquí la importància de fabricar estructures el més lleugeres possibles: reduir el cost energètic. En el cas que ens preocupava dels avions i dels coets aquesta reducció del cost energètic es reflecteix en un menor consum de combustible i, conseqüentment, del cost associat.

Però com deia la necessitat de materials més lleugers no és una preocupació exclusivament actual. Un exemple de la necessitat històrica d'utilitzar materials més lleugers es pot trobar en les bicicletes. Abans de que la bicicleta es popularitzés com a mitjà de transport, va haver de passar per un procés d'evolució progressiu que, necessàriament, va implicar la reducció del pes de l'aparell. En aquest sentit, el primer antecessor a la bicicleta que avui en dia coneixem va ser la draisina, una màquina inventada pel baró alemany Karl Drais al 1817 que va ser el primer vehicle pràctic de propulsió humana (veure Figura 4). Aquesta màquina presentava tot una sèrie d'inconvenients que dificultaven la seva popularització, un dels quals era l'elevat pes ja que, constituïda per una estructura exclusivament de ferro i fusta, aquesta pesava massa com per poder ser impulsada per una persona a través d'un mecanisme de cadena i pedals, mecanisme en el que es basen les bicicletes actuals. Així doncs, l'evolució des de les draisines fins a les bicicletes actuals no hagués estat mai possible sense una reducció del pes de l'estructura fent ús de materials més lleugers que el ferro i la fusta, com l'acer. Sense la utilització d'aquests materials lleugers, la bicicleta, tal i com avui la coneixem, segurament no existiria. I és que la reducció del pes del material, va significar poder moure la bicicleta a una velocitat bastant elevada mitjançant un sistema de cadena i pedals sense la necessitat de que la persona que la feia moure hagués de fer un esforç molt elevat 0 haguéssim de fer més gran la roda davantera.

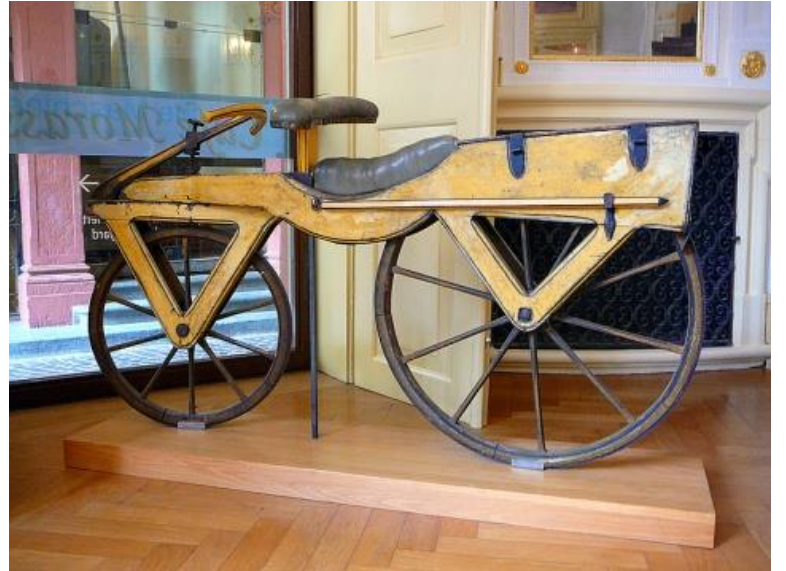

Figura 4. Prototip d'una draisina, l'avantpassat de les bicicletes, tal i com la va dissenyar Karl Drais al 1817.

\section{El procés de fabricació de la microxarxa de níquel}

Tornant a la notícia inicial, arribar a construir un material amb propietats tan interessants com la microxarxa de níquel, no és quelcom senzill i és resultat de molts anys d'investigació i d'un procés de fabricació complex. Tot i la complexitat tècnica del procés, que barreja tècniques de fotolitografia, de fibra òptica i de deposició de capes fines, aquest, bàsicament, es pot dividir en dues grans etapes: la formació d'un motlle polimèric tridimensional i la deposició del metall.

Primerament, es prepara un motlle polimèric amb l'estructura tridimensional desitjada, que serà la que li donarà les propietats desitjades a l'estructura metàl•lica. Aquest procés es fa mitjançant una tècnica basada en la generació d'una guia d'ona autopropagant. Això significa generar un feix de llum que en entrar en contacte amb la resina fotosensible se segueixi propagant a través seu sense desviar-se, traçant un camí recte. El que, en un principi, sembla tan senzill no ho és tant i és un dels punts clau en la fabricació de la microxarxa. En concret, es fan passar múltiples feixos de llum ultraviolada en determinades direccions a través d'una màscara per tal d'aconseguir un patró determinat de cel•les octaèdriques i amb una determinada forma circular. En travessar la màscara, aquests feixos incideixen sobre una resina monomèrica fotosensible líquida, és a dir, una substància líquida que en aquelles zones on és il•luminada polimeritza i, per tant, es torna sòlida degut a la interacció amb la llum ultraviolada - tal i com es fa en processos habituals de fotolitografia. La polimerització, per tant, s'inicia en aquest punt inicial d'exposició a la llum, però a causa de la diferència existent entre l'índex de 
refracció de la resina sense polimeritzar i la resina polimeritzada (que és de 0,046), tal i com passa en els cables de fibra òptica, la llum incident posterior queda atrapada en el polímer traçant una línia recta. D'aquesta manera, combinant dos grans avenços com són la fotolitografia i la fibra òptica, s'aconsegueixen formar fibres polimèriques primes al llarg del camí que segueixen els diferents feixos de llum i que degut a les direccions triades, s'entrellaçaran i generaran el què serà l'estructura tridimensional de la microxarxa una vegada s'elimini la resina que no s'ha polimeritzat (veure Figura 5).

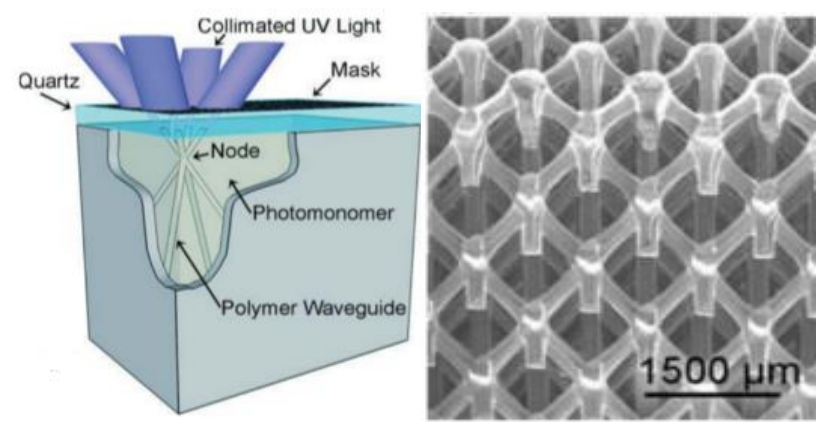

Figura 5. Representació esquemàtica de quatre guies d'ona autopropagants que s'interconnecten formant un node. (a l'esquerra); Imatge de microscòpia electrònica de rastreig (SEM) d'una microxarxa de polímer amb l'estructura de cel·les octaèdriques que es repeteix (a la dreta). (Font: Jacobsen, A.J. et al., 2007)

Un cop generat el motlle, només queda dipositar el metall sobre l'estructura. Per a tal fi es realitza una deposició conformal d'una barreja de níquel $\mathrm{i}$ fòsfor a través d'una tècnica química autocatalítica segons la qual es poden crear capes fines metàl-liques a la nanoescala $\mathrm{amb}$ un excel•lent control del gruix. Aquesta tècnica consisteix en la deposició d'un recobriment metàlolic fi sobre una superfície mitjançant una reacció de reducció segons la qual els ions metàl-lics es redueixen, en presència d'un agent reductor, al seu estat metàl•lic. La particularitat de la tècnica està en què la pròpia reacció es troba catalitzada pel mateix metall o aliatge que és dipositat, d'aquí que s'anomeni autocatalítica.

Finalment, dipositada la capa metàl-lica, s'acaba eliminant el polímer que feia de motlle, deixant tan sols el recobriment metàl•lic, per tal de formar el material macroscòpic on els elements estructurals de base són els tubs metàl-lics buits amb una espessor de 100 nanòmetres que es connecten entre sí formant cel•les octaèdriques.

\section{ALTRES MATERIALS ULTRALLEUGERS}

La microxarxa de níquel és, per tant, l'estructura metàl-lica més lleugera que es coneix en aquests moments, però ja no el material més lleuger del món. Tan sols un any després de la seva publicació va ser desbancat com a tal. L'esclat de la nanociència i la nanotecnología en els darrers anys (el que alguns anomenen la "nanorevolució"), ha obert la porta, entre moltes altres coses, a la fabricació de nous materials ultralleugers.

La utilització de nanomaterials de carboni com els nanotubs de carboni o el grafè, que presenten propietats interessants com una elevada resistència a la tracció (de $63 \mathrm{GPa}$ ) o una elevada conductivitat, respectivament, i que podrien constituir materials ultralleugers, s'han vist contínuament frenats per la falta d'avenços en el disseny d'estructures macroscòpiques que conservin aquestes propietats. Per exemple, si els nanotubs de carboni s'acoblen directament formant una corda macroscòpica la resistència a la tracció es redueix fins a aproximadament els $3 \mathrm{GPa}$ alhora que la seva densitat augmenta. A més, des d'un punt de vista de l'enginyeria, els materials amb aplicacions a la vida real requereixen mètodes de síntesi que permetin adaptar com es connecten els materials entre si així com el seu disseny morfològic.

En la línia de donar una solució a aquests problemes, des de la Universitat de Kiel es va presentar l'aerografit (veure Figura 6), un material més lleuger que les microxarxes de níquel, format exclusivament per carboni $i$ amb una densitat extremadament baixa (de fins a $0,18 \mathrm{mg} / \mathrm{cm} 3$ en el millor dels casos). Les imatges de l'aerografit amb microscòpia electrònica revelen que la seva estructura consisteix en una xarxa entrellaçada sense fissures i tancada de microtubs de grafit amb un espessor de 15 nanòmetres - similar a la dels nanotubs de carboni multiparet (veure Figura 7). A més de lleuger, aquest material també és extremadament robust, capaç de suportar fortes deformacions, i presenta hidrofobicitat. L'estructura i les propietats especials que presenta s'han aconseguit mitjançant una nova tècnica de síntesis de deposició química de vapor (Chemical Vapor Deposition - CVD) en una sola etapa basada en l'ús de xarxes lliures i ajustables d'òxid de zinc ( $\mathrm{ZnO}$ ) com a motlle. 

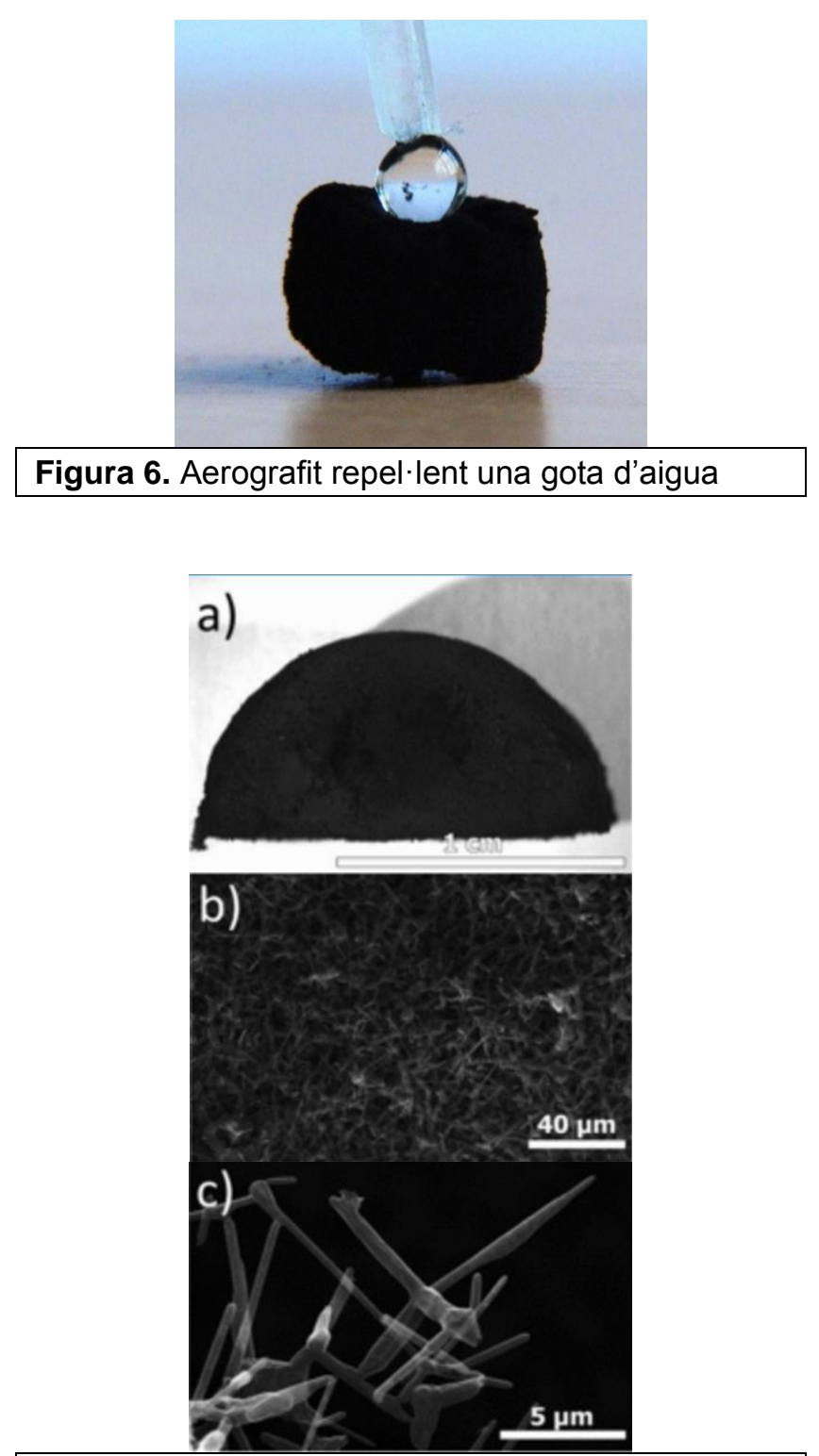

Figura 7. (a) Fotografia macroscòpica de l'aerografit. (b-c) Imatges de microscòpia electrònica de transmissió (TEM) de l'estructura tridimensional interconnectada i tancada de l'aerografit. (Font: Mecklenburg, M. et al., 2012).

Però, fins i tot un material tan lleuger com és l'aerografit s'ha vist superat per un nou material encara més lleuger: l'aerogel de grafè (amb una densitat de fins a $0,16 \mathrm{mg} / \mathrm{cm} 3$ ) (veure Figura 8). Aquest material barreja nanotubs de carboni i làmines d'òxid de grafè. Aquests dos elements es combinen formant una estructura tridimensional molt porosa de làmines de grafè plegades i orientades aleatòriament sobre les quals s'hi troba una xarxa embullada de nanotubs de carboni (veure Figura 9). Un dels avantatges de l'aerogel de grafè és la fàcil escalabilitat del procés, degut a que segueix un mètode de síntesi sense motlles (mètode "sol-cryo") i a la fàcil producció a gran escala de làmines d'òxid de grafè gegant i nanotubs de carboni, que permet sintetitzar aerogels amb la forma i la densitat desitjada.

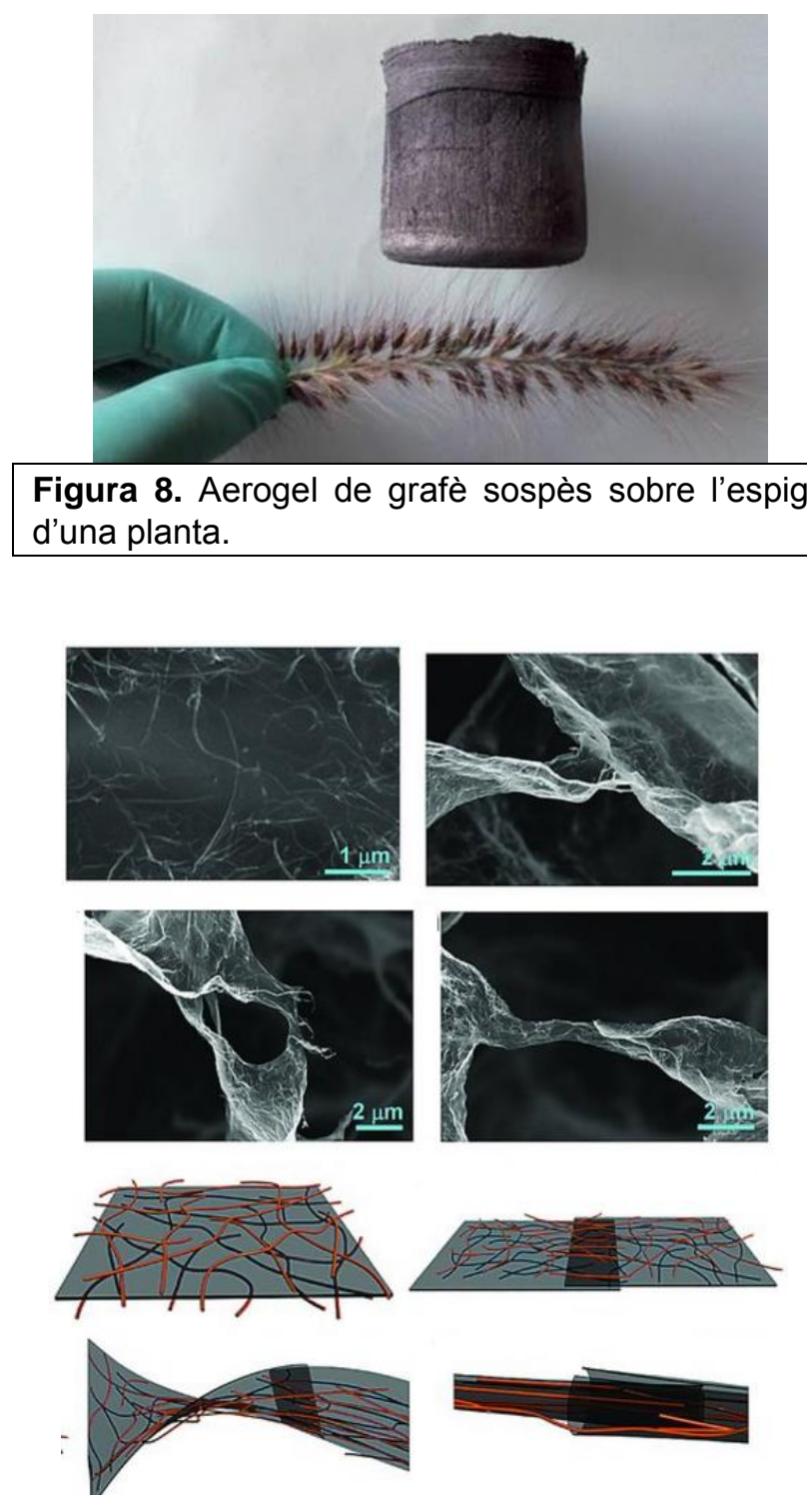

Figura 9. Imatges de microscòpia electrònica de rastreig (SEM) de diverses connexions de l'aerogel de grafè (a dalt) i models dibuixats de les diverses connexions de les imatges SEM (a baix) (Font: Sun, H. et al., 2013).

\section{ELS NOUS MATERIALS DEL SEGLE XXI}

La història de la humanitat ha estat íntimament lligada als tipus de materials que cada societat ha desenvolupat. Històricament, el desenvolupament i la evolució de les societats es relaciona amb la capacitat dels seus individus per a produir els materials necessaris per a satisfer les seves 
necessitats. Per aquest motiu, és comú classificar diverses èpoques històriques de la humanitat $a m b$ els materials utilitzats. Així doncs, tenim l'Edat de Pedra (fins aproximadament l'any $3000 \mathrm{aC}$ ) que, per la seva banda, es divideix en el paleolític (edat de la pedra antiga) i el neolític (edat de la pedra moderna). En aquestes etapes, es talla la pedra per fer objectes tallants i punxants i es comença a treballar l'argila. A continuació, trobem l'Edat del Coure (del 5000 al $1500 \mathrm{aC}$ ) on el coure desplaça a la pedra i es posiciona com el material preferit per l'home per fabricar estris i objectes cerimonials. Seguidament, arribà l'Edat del Bronze (del 2000 al $0 \mathrm{aC}$ ) quan l'home va descobrir que al barrejar estany i coure el producte resultant presentava propietats molt avantatjoses, en relació als metalls coneguts fins al moment. Més endavant, és el moment de l'Edat de Ferro (a partir del $1000 \mathrm{aC}$ ), període en el qual el ferro es descobreix i es popularitza com a material per a la fabricació d'armes i estris.

Però no va ser fins després de la Revolució Industrial, quan va aparèixer la que podríem anomenar la ciència dels materials, un camp científic encarregat d'investigar la relació entre l'estructura i les propietats dels materials. La seva aparició i posterior desenvolupament és degut als descobriments científics de la època com el de la taula periòdica o el dels raigs $X$ i la seva aplicació en el coneixement de l'estructura cristal-lina dels materials. És en aquest precís moment, quan s'aconsegueix entendre la relació entre els elements estructurals dels materials i les seves propietats, que es comencen a desenvolupar milers de materials.

Per exemple, un mateix element com el carboni pot presentar característiques molt diverses segons sigui la seva estructura molecular interna. Si es troba formant una xarxa cristal-lina cúbica centrada en les cares, trobem el diamant, un dels minerals més apreciats i cars del món. En canvi, si es troba formant unes làmines superposades entre si, trobem el grafit, el material del que està fet la mina dels llapis amb els quals escrivim. Més endavant, també es descobriria que del carboni es podien obtenir altres estructures com els fullerens, els nanotubs de carboni i el grafè.

A vegades, però, no és necessari canviar els components que formen els materials (Edat de Pedra, Coure, Bronze o Ferro) o l'estructura molecular (com en el cas del carboni), per observar propietats avantatjoses respecte a materials antics, sinó la forma de tractar els materials. Materials com la microxarxa de níquel, l'aerografit o l'aerogel de grafè són exemples d'una nova generació de materials. Materials que ens permeten observar que les propietats que exhibeixen no només depenen d'allò que estan formats - àtoms, molècules, tipus d'enllaços, etc. - i de les propietats intrínseques que se'ls hi atribueix. La configuració en l'espai, l'estructura tridimensional que donem als elements que formaran el nostre material, es demostra que també juga un paper molt important en les propietats que exhibeixen. En aquest sentit, les tècniques emprades per a la fabricació dels materials cobren una vital importància, d'aquí que es dediquin molts esforços en la investigació en noves tècniques de micro i nanofabricació, que ens ajudin a avançar cap a nous i revolucionaris materials.

\section{BIBLIOGRAFIA}

JACOBSEN, A.J.; BARVOSA-CARTER, W.B.; NUTT, S. (2007). Micro-scale Truss Structures formed from Self-Propagating Photopolymer Waveguides. Advanced Materials 19 (22): 38923896. doi:10.1002/adma.200700797.

US PATENT 7382959, ALAN J. JACOBSEN, Optically oriented three-dimensional polymer microstructures, assigned to HRL Laboratories, LLC.

SCHAEDLER, T.A.; JACOBSEN, A.J.; TORRENTS, A.; SORENSEN, A.E.; LIAN, J.; GREER, J.R.; VALDEVIT, L.; CARTER, W.B. (2011). Ultralight Metallic Microlattices. Science 334 (6058):962-5.

MECKLENBURG, M.; SCHUCHARDT, A.; MISHRA, Y.K.; KAPS, S.; ADELUNG, R.; LOTNYK, A.; KIENLE, L.; SCHULTE, K. (2012). Aerographite: Ultra Lightweight, Flexible Nanowall, Carbon Microtube Material with Outstanding Mechanical Performance. Advanced Materials 24 (26): 3486-90. doi:10.1002/adma.201200491.

SUN, H., XU, Z. AND GAO, C. (2013), Multifunctional, Ultra-Flyweight, Synergistically Assembled Carbon Aerogels. Advanced Materials 25: 2554-2560. doi:10.1002/adma.201204576 